\title{
A geochemical investigation of the sensitivity of a normally consolidated clay from Drammen, Norway
}

MOUM, J., LÖKEN, T. and TORRANCE, J. K. (1971). Géotechnique 21, No. 4, 329-340.

\section{B. Balasubramonian and N. Morgenstern, Department of Civil Engineering, University of Alberta, Edmonton, Alberta, Canada}

The Writers have read the Paper with great interest and the Authors are to be congratulated for their effort to delineate the dependence of sensitivity on geochemistry.

Numerous previous investigations have identified the (total) pore water salinity as one major cause contributing to sensitivity, e.g. Bjerrum and Rosenquist (1956). However, recent works (Talme, 1968 and this Paper) help to demonstrate that the individual ion distribution in the pore water could affect the sensitivity of the soil as well.

In the present study, the pore water has been extracted from the soil sample from various depths from two holes $25 \mathrm{~m}$ apart. The conductivity measurements of these pore waters indicate that the total salinity is practically constant with depth and between the two holes. The total salt concentration can also be estimated from the cation concentrations reported in Tables 1 and 2 of the Paper. Such total salinities calculated from the cation concentrations have been compared in Fig. 1 with those found from the conductivity measurements. The comparison between the two total salinities seems good for hole 2 ; but the difference between the two estimated values is beyond acceptable limits for hole 1. This probably has resulted from an error in the concentration of $\mathrm{Mg}$ in hole 1 . Comparing holes 1 and 2 , one can see that the concentration of $\mathrm{Mg}$ in hole 1 is almost ten times that of the same ion in hole 2 and that the concentration of all other ions is within a close range. The total salinity calculated using one-tenth of the reported $\mathrm{Mg}$ concentration gives a value comparable with that predicted from the conductivity data for hole 1 (Fig. 1). Therefore, the Writers suspect that the Mg concentration reported for hole 1 is ten times the actual value.

The undisturbed shear strength has been reported to be constant with depth in both holes (Figs 2 and 3 of the Paper). Hence the sensitivity of the soil with depth is proportional to the inverse of its remoulded shear strength. Since the total salinity and the soil type are essentially constant with depth (a slight increase in salinity towards the surface may be seen in Fig 1-this is probably because of the predominantly upward leaching in this area as reported in the Paper), the variation of the remoulded shear strength arises from a variation of the individual ion concentration in the pore fluid. This has been investigated by the Authors by adding salts of $\mathrm{K}, \mathrm{Mg}$ and $\mathrm{Ca}$ to the quick clay samples from $8.5-10.5 \mathrm{~m}$ in hole 2. From these tests they conclude that $\mathrm{K}$ and $\mathrm{Mg}$ have a pronounced effect on the remoulded strength of the soil. However, it is not clear from the Paper whether the salts have been added to the soil at its natural water content, in which case the total pore water salinity varies with increasing addition of salt, or whether the salts were added to a soil monoionized with the cation of that particular salt, in which case the Writers doubt whether these results are applicable to a natural soil with a multiple exchangeable ion complex. In this context, the Writers wish to take a different approach than the one taken in the Paper.

The proportion of the various exchangeable cations may be related to the distribution of individual cations in the pore water through an empirical equation called Gapon's equation, e.g. Yong and Wankentin (1966).

$$
\frac{M_{\mathrm{e}}}{D_{\mathrm{e}}}=k \frac{M_{\mathrm{o}}}{D_{\mathrm{o}}{ }^{1 / 2}}
$$




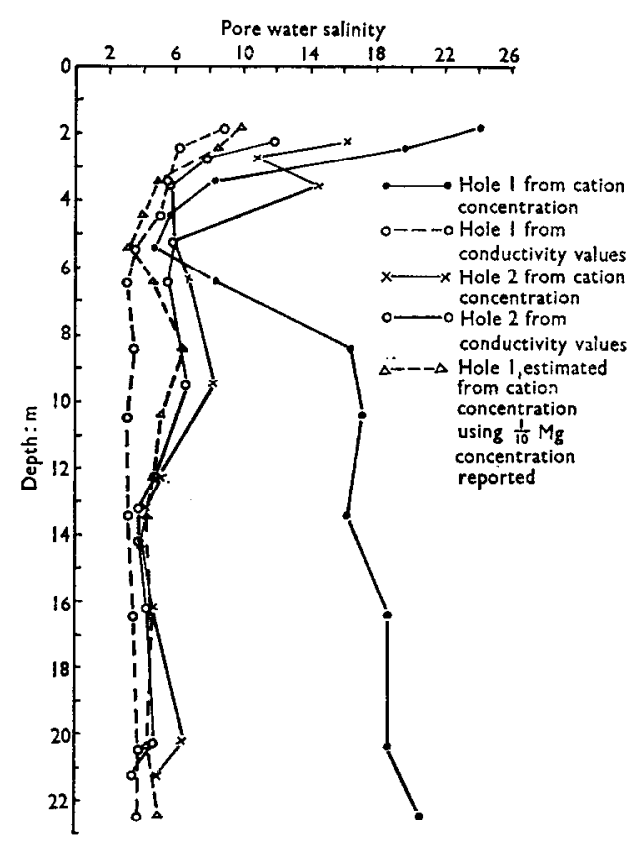

Fig. 1. Variation of pore water salinity with depth

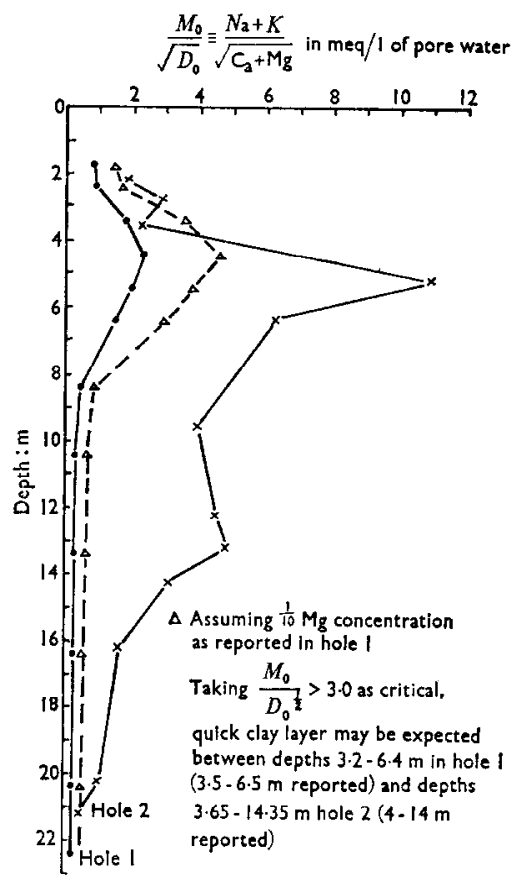

Fig. 2. Variation of $M_{0} / \sqrt{ } \overline{D_{0}}$ with depth

where $M_{0}, D_{\mathrm{o}}=$ molar concentration of the monovalent, divalent cations in the free pore water, $M_{\mathrm{e}}, D_{\mathrm{e}}=$ the exchangeable monovalent, divalent cation in meq $/ 100 \mathrm{~g}$ of air dry soil, and $k=$ Gapon's constant (depends on soil type).

This equation suggests that a plot of $M_{\mathrm{o}} / D_{\mathrm{o}}{ }^{1 / 2}$ with depth would indicate the variation of the monovalent/divalent ion ratio in the exchangeable complex for the soil in the field provided the soil type (and hence $k$ ) is constant with depth. This condition is satisfied by the clay in Drammen. Such a plot is shown in Fig. 2 where $M_{0}$ and $D_{\mathrm{o}}$ are expressed in meq/l instead of molar concentrations as suggested in the equation. It can be seen in this figure that $M_{\mathrm{o}} / D_{0}{ }^{1 / 2}$ shows a substantial increase within the depths reported to be quick. The quick clay layer has been reported to be present between 3.5 and $6.5 \mathrm{~m}$ in hole 1 and between 4 and $14 \mathrm{~m}$ in hole 2, where the ratio $M_{\mathrm{o}} / D_{\circ}{ }^{1 / 2}$ is greater than about 3 (Fig. 2). This figure clearly indicates that the sensitivity is influenced by not merely the total salinity but by the distribution of the individual salts in the pore water (and hence the ions in the exchangeable complex) as well.

The salinity at the depths where quick clay was found in hole 2 is larger than far below. However, in this zone the concentration of the monovalent ions was much larger and the concentration of the divalent ions was much smaller than in other regions. This has resulted in a more sensitive soil in that region. Also, the variation of the ratio $M_{\mathrm{o}} / D_{\mathrm{o}}{ }^{1 / 2}$ bears some relation to the variation of the sensitivity of the soil from both the holes reported in the Paper. Such a variation with depth may be used in future studies at least for diagnostic purposes to delineate the presence of highly sensitive soil.

The mechanism that causes sensitivity for such a soil may be explained as follows. These clays have been deposited in a marine environment. This leads to the formation of a flocculated structure initially. When this material is consolidated under the overburden pressure, the soil comes to equilibrium at a high void ratio compared with the final void ratio that will 
be reached by the same soil with a more dispersed structure. Subsequent leaching of this soil with a comparatively salt-free water has resulted in either a reduction of salinity and/or a change in the distribution of individual salts in the pore water at some depths. This leaves the soil in a meta-stable structurc. Remoulding this soil results in the collapsc of its fabric to a more dispersed one. Part of the load that was carried by the soil skeleton is now thrown on the pore water. (An increase in the pore water pressure on remoulding a sand-clay mixture has been reported by Mitchell and Houston (1969).) This results in a decrease in the effective stress and a subsequent reduction of the remoulded shear strength of the sample. Between two samples of the same soil with essentially similar fabric and salinity, the one with a higher monovalent ion concentration will be expected to reach a more dispersed structure (and therefore less effective stress) than another sample with a high proportion of divalent ions. Since the ficld strength is a constant at all depths for this soil, the region where the exchangeable monovalent/divalent cation ratio was maximum has resulted in a lower remoulded strength and hence a higher sensitivity.

This Discussion shows that the sensitivity of such a soil for which the total salinity, soil type and the field strength are constant with depth may be studied in terms of $M_{0} / D_{0}{ }^{1 / 2}$. This approach assumes the validity of Gapon's equation. This equation does not differentiate between two ions with the same valency, e.g. between $\mathrm{Na}$ and $\mathrm{K}$ or between $\mathrm{Ca}$ and $\mathrm{Mg}$. Further research on the effects of each of these ions on the strength of a soil with a multiple exchangeable ion complex is warranted before a more generalized theory can be proposed.

\section{REFERENCES}

Bjerrum, L. \& Rosenquist, I. Th. (1965). Some experiments with artificially sedimented clays. Géotechnique 6, No. 3, 124-136.

Mitchell, J. K. \& Houston, W. N. (1969). Causes of clay sensitivity. Jnl Soil Mech. Found. Div. Am. Soc. Civ. Engrs. 95, SM3, 845-871.

Talme, A. O. (1968). Clay sensitivity and chemical stabilization. Byggforskningens Rapport 5b, Stockholm. The National Swedish Institute for Building Research.

Yong, R. N. \& Wankentin, B. P. (1966). Introduction to soil mechanics. New York: McMillan Series in Civil Engineering. 